\title{
Research on the Influence Mechanism of Social Shopping Community on Consumers' Purchase Intention
}

\author{
—Based on attachment theory
}

\author{
Zhao Haoxing \\ School of Business Administration \\ Zhejiang Gongshang University \\ Hangzhou 310000, China
}

\author{
Peng Jianxiong* \\ School of Business Administration \\ Zhejiang Gongshang University \\ Hangzhou 310000, China \\ *Corresponding author
}

\begin{abstract}
With the development of social media and e-commerce, the social shopping community has emerged and developed. The methods of this new socialized e-commerce model's influences on consumers' willingness to purchase have received widespread attention from the academic community and the industry. Based on the attachment theory, this paper uses the empirical analysis method to examine the influence of the sharer characteristics and technical characteristics of the social shopping community on consumers' purchase intention. The research results show that emotional attachment plays an intermediary role in the relationship between sharer characteristics and purchase intention and show that functional dependence plays an intermediary role in the relationship between technical characteristics and purchase intention.
\end{abstract}

Keywords-social shopping community; note-sharing characteristics; technical characteristics; attachment theory; purchase intention

\section{INTRODUCTION}

With the development of virtual communities and e-commerce, numerous new business models have emerged and the social shopping community is one of them. Represented by beautiful stories, Mushroom Street, and Xiao Hongshu, the social shopping community functions with the core of sharing, shopping guide and shopping. It has created a social e-commerce shopping guide model, which solved selection difficulties and information asymmetries in the users' online shopping process. Taking Xiao Hongshu as an example, Xiao Hongshu was just a simple UGC (User-Original Content) shopping note sharing community at the beginning. It used a high-quality shopping sharing community to attract a large number of users, and based on this, it established a self-operated shopping platform to transform users' behaviors. The shopping and sharing platform is the first highlight of Xiao Hongshu , and it is also the core function as well as the core competitiveness of it. Until the end of October 2017, the number of Xiao Hongshu users exceeded 70 million, and $70 \%$

This article is supported by the 2016 Key Project of the Humanities and Social Science Research Base of the Ministry of Education, "The Research on Innovation and Competitiveness Improvement of Chinese Circulation Enterprises in the Context of Internet Economy" (16JJD790055), thanks for this. of new users were young users after 95.

Although the social shopping community has developed rapidly in China, the methods of motivating consumers' desire to purchase and converting traffic into cash flow are still the most important issue faced by all communities. From the perspective of attachment theory, this paper starts from note-sharing and technical characteristics, and explores the mechanism of social shopping community's influence on consumers' purchase intention through the methods of literature research and empirical analysis.

\section{Literature REVIEW AND RESEARCH HyPOTHESIS}

In recent years, with the rapid development of virtual communities and e-commerce, relevant scholars have studied a lot ${ }^{[1-4]}$. However, the product of the combination of the two, the social shopping community, has been studied little since its inception. Only a few scholars have conducted researches, and researches have mainly explored the factors that influence consumers' purchase intention from the perspective of trust and perceived value ${ }^{[5-6]}$.

To sum up, from the point of intermediary factor, few researchers have studied from the perspective of consumer attachment about the research of social shopping communities. Through in-depth interviews, this study finds that the note-sharing and technical characteristics in the social shopping community have a significant impact on consumers' purchase intention. Therefore, it is of great theoretical and practical value to explore the mechanism through the attachment theory.

\section{A. Note-sharing and technical characteristics of social shopping community}

\section{1) Social shopping community}

According to the characteristics of the social shopping community, the study modified the definition of the social shopping community in the Kang \& Johnson study. Namely, the social shopping community is a kind of virtual space. In this space, sharers can publish their recommendations and review information on the product, show the pictures when 
they use the product and help the user to seek product suggestions to assist with purchase decisions, and form an online, interactive, shared consumer community ${ }^{[7]}$.

\section{2) Note-sharing of social shopping community}

According to Gilly M C and others, the definition of shared entities in the virtual community is "The knowledge sharing entity is an important component of the knowledge sharing activities and the main body of the knowledge sharing in the virtual community is the community members, including knowledge senders and receivers ${ }^{[8] \text {," }}$. This study mainly explores the impact of sharer characteristics on consumer purchase intention in social shopping community, hence defining sharer as note-sharer. According to the characteristics of the research object of this paper, we use Chang Ya's equality to divide the sharer and the sharer is divided into the professional ability of the sharer, the strength of the relationship with the recipient, and the status of the community [4]

According to Bristor's definition of professional competence, professional competence means that information recipients believe the information recommender has the ability to offer correct information. This ability is not necessarily the actual ability of the information recommender, but the subjective judgment of the information receiver based on past purchase experience and product cognition of the information recommender ${ }^{[9]}$ through mutual interaction.

Brown describes the strength of relationship as familiarity between the source of information and the recipient of information ${ }^{[10]}$. On the basis of this, Chang Yaping defines the strength of relationship as the closeness degree of the community relationship between the recipient and the sender of information. It is embodied in the four dimensions-- intimacy, familiarity, similarity, and support between the sender and the recipient of information ${ }^{[4]}$.

Chang Yaping believes that the sender's community status refers to the level and community influence of the sender in the virtual community, which can be shown in the prestige of the community, the number of posts/replies, and the degree of enthusiasm, essence, etc. ${ }^{[4]}$.The position of the leader who proposed opinions is reflected in: 1 . Having a dominant and influential position in the field; 2 . Having a certain reputation and prestige in society; 3 . Being widely known in forums or communities $^{[11]}$.

3) Technical characteristics of social shopping community

According to the research of relevant scholars, Animesh and others proceeded from the virtual world scenario, dividing the technical characteristics of the website into social and interactive dimensions ${ }^{[12]}$. Based on the study of social shopping community, Zhang Hong and others found that social shopping community has two important technical features--sociality and self-referencing. Hence, this paper divides the technical characteristics of the social shopping community into two dimensions-- personalized recommendation and social interaction ${ }^{[6]}$.

\section{B. Attachment theory}

The earliest attachment theory was proposed by Bowlby, which was used to describe a unique emotional bond formed between an individual (infant) and a specific subject (mother or primary caregiver) and evolved into relations of relatives, friendships, and romance ${ }^{[13]}$. Subsequently, the attachment theory was applied to the field of consumer research by marketing scholars, which derived the consumer attachment theory of belongings, brands, companies, places, and websites. Research by Reichheld and Schefter shows that websites are attractive because of the super information base they contain. The websites are very popular with consumers and they strongly attract consumers to browse again ${ }^{[14]}$. Wan $\mathrm{J}$ and others think that attachment is one of the factors that promote commitment, loyalty and consumer assistance behavior. When users are emotionally attached to the target audience, they may spend more time, energy and financial resources to strengthen the relationship. In the virtual context, due to lack of social pressure, and because of the prevalence of free and popular, note-sharing participants must ensure that their "consumer notes" can attract potential users with the same interests and interests, and that users can create attachments. Therefore, we use attachment theory to explain why users are willing to shop on social shopping sites ${ }^{[15]}$. Based on this, the study divides attachment into emotion attachment to the sharer and functional dependence of the community platform.

\section{Relationship between sharer characteristics and emotional attachment of social shopping community}

\section{1) Relationship between strength and emotional attachment}

Smith and others found that the similarity between consumers promotes their emotional ties and pushes forward the rapport and strength of connections ${ }^{[17]}$. Hu X and others believe that if the user perceives a highly overlapping personality between self-personality and the content creator, the user will have a sense of identity with the content creator, which makes the user dependent on the content creator and hopes to establish a relationship with them ${ }^{[5]}$. Therefore, this study proposes the following assumptions:

H1: The strength of the relationship between note sharers and consumers in the social shopping community positively influences the emotional attachment of the consumer.

2) Relationship between professional competence of sharer and emotional attachment

Mitchell and others found in the study that the information possessed by professional experts has a crucial influence on the choice of product buyers ${ }^{16]}$. For the average consumer, because they do not have adequate information about the product, they tend to adopt the information recommended by experts in the absence of purchase experience. Therefore, this study proposes the following assumptions:

H2: The professional ability of the sharer positively affects the emotional attachment of consumers.

3) Relationship between community status of sharer and emotional attachment

Mayer R C and others view that compared with ordinary community members, high-status members have higher social participation and higher exposure. They are at the core of the community and can give their opinions through their own experiences, and have a greater impact on ordinary users ${ }^{[18]}$. 
And if the source of information is opinion leaders, the influence on consumers is much greater than that of non-opinion leaders ${ }^{[11]}$. Therefore, this study proposes the following assumptions:

H3: The social status of note sharers in the social shopping community positively affects the emotional attachment of consumers.

\section{Relationship between technical characteristics and} functional dependence of social shopping community

1) Relationship between personalized recommendation and functional dependence

Komiak believes that the social shopping community offers users user recommendations that will allow them to trust that the community will consider their personal preferences rather than base on the community's own interests, thereby enhancing their perception of the impartiality and objectivity of information provided by the community ${ }^{[19]}$. Rad and others point out that when promoting products, the behavioral data of friends with similar interests are included in the recommendation, and these recommendations are practical and relevant in order to reach the expectation of users and find products that even users hard to find ${ }^{[20]}$. Zhang Hong and others point out that self-referential information can better represent consumers' personal preferences than non-self-referencing ${ }^{[6]}$. Therefore, this study proposes the following assumptions:

H4: Personalized recommendations positively influence consumer's functional dependence.

2) Relationship between social interaction and functional dependence

Zhao Ling and others believe that if a social shopping community has a higher level of sociality; it will promote more social interaction between users ${ }^{[2]}$. While Short and others believe that this kind of technological environment with higher social skills may promote more intense emotions, trust, and sense of belonging among users ${ }^{[21]}$. Orth and others think that this in turn will enhance the perception of social media attachment ${ }^{[22]}$. Therefore, this study proposes the following assumptions:

H5: Social interaction positively influences consumers' functional dependence.

\section{E. Relationship between functional dependence and purchase intention}

Jackson, Trauer, Ryan and others think that functional dependence is how the system supports the achievement of user goals under certain circumstances and conditions ${ }^{[23-24]}$. $\mathrm{Wu}$ believes that functional dependence affects user's emotional state and behavior ${ }^{[25]}$. Thomson, Johnson, Rapp and others research and believe that the strength of an individual's dependence on an object may be related to the investment in the object and the willingness to sacrifice money to obtain the object, or to help achieve its goals, such as paying high prices or performing additional tasks ${ }^{[26-27]}$. Wan and others believe that social shopping websites provide technical support for users, enabling users to communicate, share, consume knowledge and follow other users ${ }^{[15]}$. For this reason, this study proposes the following assumptions:

H6: Consumers' functional dependence on the shopping community positively influences their purchase intentions.

\section{F. Relationship between emotional attachment and purchase intention}

Choi.N believes that if the user is attached to product, person, or object, he will be willing to spend more resources (such as time and energy) returning to other users' questions or putting forward suggestions. In the study of the relationship between consumers and celebrities, emotional attachment plays an important role in explaining behavior of consumers and fans ${ }^{[28]}$. In addition, according to Wan $\mathrm{J}$ and others' research on donations, donors are willing to donate to their trusted organizations. So we will attribute the emotional attachment of recommenders to the emotional connection between users and recommenders in this study. It reflects the user's emotional commitment and hopes to contact and strengthen connection with the recommender ${ }^{[15]}$. Therefore, this study proposes the following assumptions:

H7: The emotional attachment of consumers to the note sharers positively influences their purchase intentions.

\section{G. Research model}

Based on the above research hypothesis, this study proposes to build a research model by using the social shopping community sharer characteristics and technical characteristics as independent variables; emotional attachment and functional dependence as mediators; and consumer purchase intention as dependent variables. It is shown in Fig. 1.

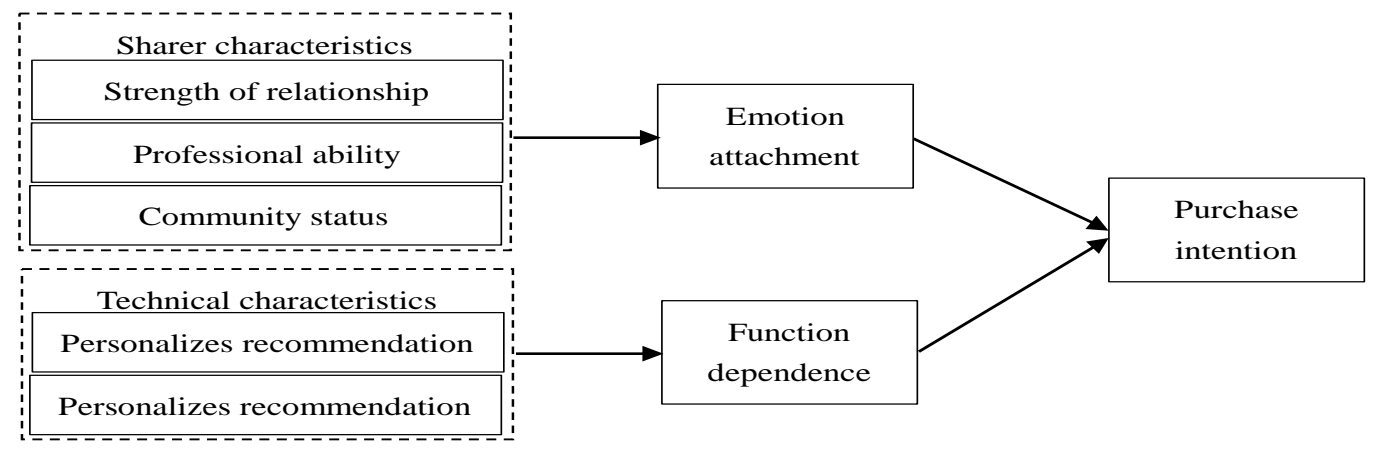

Fig. 1. Research model 


\section{RESEARCH DESIGN}

\section{A. Sources of the scale}

Based on the characteristics of the social shopping community, this study uses the Likert seven-grade scale (1=strongly disagree, $7=$ =strongly agree) to measure variables. The measurement methods for each scale are as follows:

1. Relationship. Mainly refer to the Gilly (1998) ${ }^{[8]}$, Shen etc. (2010) ${ }^{[29]}$ scale, four questions are used for measurement.

2. Professional ability. Mainly refer to Smith (2002) ${ }^{[17]}$, Wang Tao \& Li Yanping (2007) ${ }^{[1]}$, Chang Yaping(2010) ${ }^{[4]}$ related scales, a total of three measurement problem items.

3. Community status. Mainly refer to Chang Yaping $(2010)^{[4]}$ measurement scale of community status, using three problem items to measure.

4. Personalized recommendation. Mainly refer to Kumar \& Benbasat (2006) ${ }^{[31]}$ related scales; a total of three questions are measured.

5. Social interaction. Mainly refer to the Phang etc. (2010) [32] correlation scale; three problem items are used for measurement.

6. Emotional attachment. Mainly refer to Ren Y etc. (2012) [33] correlation scale; three problem items were used for measurement.

7. Functional dependence. Mainly refer to Antioco $\mathrm{M}$ etc. (2008) ${ }^{[34]}$ related scale; three problem items are for measurement.

8. Purchase intention. Mainly refer to Bristor (1990) ${ }^{[9]}$, Smith (2002) ${ }^{[17]}$, Chen Xiaolei (2008) ${ }^{[35]}$, Zheng Xiaoping (2008) ${ }^{[36]}$ measurement scale; three problem items are for measurement.

\section{B. Research sample and data collection}

The study mainly collects samples through questionnaire surveys. A total of 300 questionnaires were distributed and 283 were recovered, of which 254 were valid questionnaires. Among the respondents, men accounted for $13.27 \%$, women accounted for $86.73 \%$, and the proportion of women was significantly higher than men; the age distribution and education of the study subjects: $92.53 \%$ were between 18-25 years old, and bachelor's degree or above accounted for $97.45 \%$, except for sample selection is mainly for students outside the school. It also shows that the social shopping community is generally young and highly educated. This group of people is more likely to try fresh. In terms of use time, $48.47 \%$ of people use social shopping community for more than one year, which reflects that the social shopping community is still in the development stage compared with the pure e-commerce platform, and the usage rate is not universal enough.

\section{Data analysis}

1) Reliability and validity analysis

This paper uses Cronbach's a coefficient to examine the reliability of the questionnaire. SPSS 21.0 statistical software is used to test the reliability of the sample data. According to the results, the Cronbach's coefficients of all variables were all above 0.7 , indicating that the scale had high internal consistency and the questionnaire was highly reliable. What's more, the component factor analysis further validated the validity of the questionnaire. Questions all pass the Bartle's sphericity test. The KMO value is basically around 0.7 , and the cumulative variance interpretation percentage was basically around $70 \%$, indicating that the scale had a better structure validity, as shown in TABLE I.

TABLE I. ANALYSIS RESULTS OF VARIABLES RELIABILITY VALIDITY

\begin{tabular}{lccc}
\hline \multicolumn{1}{c}{ Variables } & Cronbach’s Alpha & KMO Values & Cumulative explanatory variances \\
\hline Strength of relationship & 0.787 & 0.772 & $61.420 \%$ \\
Professional ability & 0.803 & 0.683 & $71.808 \%$ \\
Community status & 0.824 & 0.720 & $74.004 \%$ \\
Personalizes recommendation & 0.860 & 0.731 & $78.164 \%$ \\
Social interaction & 0.792 & 0.686 & $70.696 \%$ \\
Emotion attachment & 0.770 & 0.687 & $68.674 \%$ \\
Function dependence & 0.781 & 0.702 & $69.504 \%$ \\
Purchase intention & 0.725 & 0.681 & $64.591 \%$ \\
\hline
\end{tabular}

\section{2) Structural equation model analysis}

This article uses AMOS21.0 software for statistical analysis of samples and the analysis results are shown in Figure 2, Table 2, Table 3 . According to the result equation model fitting indicator, $\chi 2 / \mathrm{df}$ is $2.913<3$; RMSEA is $0.087<0.09$; CFI is
$0.777>0.7$; GFI is $0.770>0.7$; AGFI is $0.724>0.7$. Every indicator is within an acceptable range, which shows that the model has a good fit. According to the structural equation model analysis results, the research hypothesis has been effectively verified. 


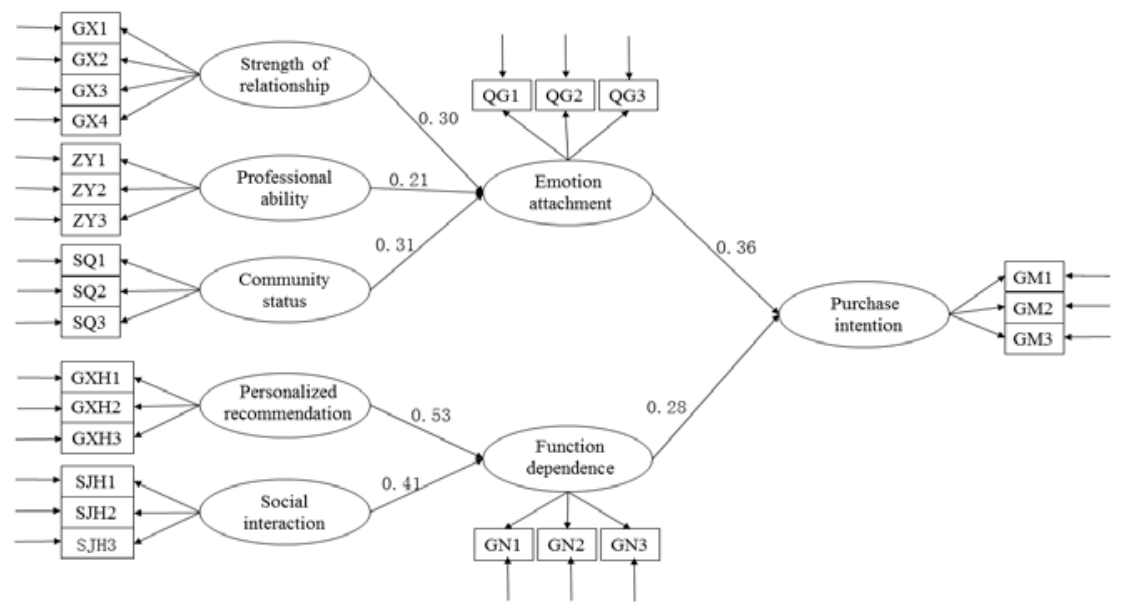

Fig. 2. Structural equation model

TABLE II. MODEL ANALYSIS RESULTS

\begin{tabular}{|c|c|c|c|}
\hline Path hypothesis & Estimate & C.R. & $\mathrm{P}$ \\
\hline Emotion attachment $\leftarrow$ Strength of relationship & .297 & 4.646 & $* * *$ \\
\hline Emotion attachment $\leftarrow$ Professional ability & .212 & 3.406 & $* * *$ \\
\hline Emotion attachment $\leftarrow$ Community status & .306 & 4.928 & $* * *$ \\
\hline Function dependence $\leftarrow$ Personalized recommendation & .528 & 8.607 & $* * *$ \\
\hline Function dependence $\leftarrow$ Social interaction & .408 & 6.300 & $* * *$ \\
\hline Purchase intention $\leftarrow$ Function dependence & .280 & 2.682 & .007 \\
\hline Purchase intention $\leftarrow$ Emotion attachment & .365 & 2.402 & .016 \\
\hline
\end{tabular}

TABLE III. MODEL FITTING INDICATOR

\begin{tabular}{lccccl}
\hline Fitting indicator & $\mathrm{X}^{2} / \mathrm{df}$ & RMSEA & GFI & AGFI & CFI \\
\hline Specific indicator & 2.913 & 0.087 & 0.770 & 0.724 & 0.777 \\
\hline
\end{tabular}

\section{CONCLUSIOnS AND Discussions}

\section{A. Research conclusions}

1) An intermediary role plays in emotional attachment between sharer characteristics and purchase intention

Empirical analysis shows that emotional attachment plays an intermediary role between sharer characteristics and purchase intention (the path coefficients between relationship strength, professional competence, and community status are $0.297,0.212$, and 0.306 respectively; $p$-values are all less than 0.05; the path coefficient between purchase intention and emotional attachment is 0.365 , and the p-value is less than 0.05).Note sharers interact with the users online and offline or in the community, which helps the user to create attachments to the note sharers and enhances the users' willingness to purchase through the users' understanding of the products shared by the note sharers. The more professional the note sharers are, the easier it is for users to trust, and users are more willing to browse their note, which in turn creates attachments and then a desire to purchase. High-ranking note sharers are like opinion leaders. Consumers are the first to pay attention to the high prestige value, the more essence of notes, because these notes have been recognized by most users. Note sharers can easily make users attached by writing high-quality notes; hence obtaining advantages over the users' intention to purchase.
2) An intermediary role plays in function dependence between technical characteristics and purchase intention

Empirical analysis shows that function dependence plays an intermediary role between technical characteristics and purchase intention (the path coefficients between personalized recommendation and social interaction are 0.528 and 0.408 respectively; p-values are all less than 0.05 ; the path coefficient is 0.280 between function dependence and purchase intention, and the p-value is less than 0.05). The platform analyzes and processes background data to provide users with accurate personalized recommendation. This enables users to feel good about the community and believes that the community is genuinely thinking for themselves and hence generating purchase intention. Similarly, the social interactions provided by the community can help users from little understanding to an understanding about the product, from an understanding to an in-depth understanding, arousing the users' social desire and the desire to purchase the product.

\section{B. Management inspiration}

Based on existing research findings and the current research results, this paper mainly starts from the social shopping community itself, and proposes the following management inspirations on measures that should be taken by the social shopping community to enhance user attachment and transfer user traffic to cash flow. 


\section{1) Stay in close contact with users}

Research shows that relationship strength is one of the important factors that affect the user's willingness to purchase, and strengthening the relationship with the user will help the user to generate purchase intention. A close connection will enhance the emotional bond of the user, hence promoting the harmonious relationship. Compared with other infrequent contacts, the close connection makes it easier for the user to generate purchase intention.

\section{2) Improve professional ability of note sharers}

Research points out that the professional ability of the note sharers significantly affects the user's willingness to purchase. When note sharers are familiar with the product and have rich experience in purchasing and using, the user will be more willing to believe such notes. Therefore, the social shopping community should use rational and scientific technical means to accurately divide the user groups and understand the different needs of the users. For the subdivided areas, the social shopping community should invite or nurture professionally competent "experts" and "leaders" to enter into the community and publish consumption notes that help users understand what they want to understand and clear out information mismatch issues.

\section{3) Pay attention to the accuracy of recommended} information

Accurate recommendations will allow users to appreciate the attention of the community, and will make users believe that the community will consider their personal preferences rather than the community's own interests, thereby enhancing the perception of user's information impartiality and objectivity to the community. Hence, the community can analyze the user's habits through the user's frequently browsed or bookmarked notes, and send recommendations precisely for their interests and hobbies to help them achieve their goals more quickly and accurately.

\section{4) Making full use of social interaction}

Studies show that high social skills in the technical environment may make users create a stronger sense of emotion, trust and belonging. Through providing interactive functions such as commenting, praising, collecting and sharing, the community helps users understand products that they would like to buy but do not understand. And in an interactive atmosphere, they can stimulate users' desire to buy, and purchase without purchase intention.

\section{Research limitations}

This study has some limitations: First, the sample source is mainly students from universities. Their economic capacity is limited and the sample representation is not strong, which indirectly affects the universality of the research results; second, the study only discuss the influence of sharer characteristics and technical characteristics on consumer purchase intention, and it does not take into account the influence of the community's own popularity; third is the division dimension of the sharer characteristics, the study divides the sharer characteristics into the most representative three dimensions according to previous studies without considering other dimensions; fourth, the research object is the willingness to buy, not the purchase. In the follow-up research process, the above issues should be fully considered.

\section{REFERENCE}

[1] Wang Tao, Li YP, WANG Tao, et al. The influence of recommendation characteristics on recommendation effect in Virtual Community [J]. Business economy and Management,2007(11):50-55.(In Chinese)

[2] Zhao Ling, Lu Yaobin, Deng Chaohua. A study on Trust and purchase behavior of Community members in Virtual Community [J]. Industrial Engineering and Management,2009, 14(3):105-111. (In Chinese)

[3] Pan Yu, Zhang Xing, Gao Li. A study on factors influencing consumers willingness to purchase in online Retailing: an Analysis based on Trust and perceived risk [J]. China's Industrial Economy, 2010(7):115-124. (In Chinese)

[4] Chang YP, Qiu Yuanyuan, Yan Jun, et al. Study on the Mechanism of knowledge sharing in Virtual Community on the first purchase intention [J]. Management Science,2011, 24(2):74-84. (In Chinese)

[5] Hu X, Huang Q, Zhong X, et al. The influence of peer characteristics and technical features of a social shopping website on a consumers purchase intention[J]. International Journal of Information Management the Journal for Information Professionals, 2016, 36(6):1218-1230.

[6] Zhang Hong, Lu Yaobin, Yan Yan Ling. Influence of socialized shopping community technology characteristics on purchase intention [J]. Research Management,2017, 38(2):84-92. (In Chinese)

[7] Johnson K K P, Kang J Y M. How does social commerce work for apparel shopping? Apparel social e-shopping with social network storefronts[J]. Journal of Customer Behaviour, 2013, 12(1).

[8] Gilly M C, Graham J L, Wolfinbarger M F, et al. A dyadic study of interpersonal information search[J]. Journal of the Academy of Marketing Science, 1998, 26(2):83-100.

[9] Bristor J M. Enhanced explanations of word of mouth communications: The power of relationships[J]. Research in Consumer Behavior, 1990, 4(1):51-83.

[10] Brown J J, Reingen P H. Social Ties and Word-of-Mouth Referral Behavior[J]. Journal of Consumer Research, 1987, 14(3):350-362.

[11] Meng Fei. A study on the influence of opinion leaders on purchase intention in the context of Social Business [D]. Nanjing University,2012. (In Chinese)

[12] Animesh A, Pinsonneault A, Yang S B, et al. An odyssey into virtual worlds: exploring the impacts of technological and spatial environments on intention to purchase virtual products[J]. Mis Quarterly, 2011, 35(3):789-810.

[13] Bowlby J M. Attachment and Loss: Vol. 1[J]. 1969(4):595-599.

[14] Reichheld F F,Schefter p.E-loyalty[J],Harvard Business Review, 78(4):105-113

[15] Wan J, Lu Y, Wang B, et al. How attachment influences users' willingness to donate to content creators in social media: A socio-technical systems perspective[J]. Information \& Management, 2016.

[16] Smith D, Menon S, Sivakumar K. Online peer and editorial recommendations, trust, and choice in virtual markets[J]. Journal of Interactive Marketing, 2005, 19(3).

[17] V. - W. Mitchell, Boustani P. A Preliminary Investigation into Pre and Post - Purchase Risk Perception and Reduction[J]. European Journal of Marketing, 1994, 28(1):56-71.

[18] Mayer R C, Davis J H, Schoorman F D. An Integrative Model Of Organizational Trust[J]. Academy of Management Review, 1995, 20(3):709-734.

[19] Komiak S Y X, Benbasat I. The Effects of Personalization and Familiarity on Trust and Adoption of Recommendation Agents[J]. Mis Quarterly, 2006, 30(4):941-960.

[20] Rad A A. A Model for Understanding Social Commerce[J]. Journal of Information Systems Applied Research, 2011, 4(2):6373.

[21] Short J, Williams E, Christie B. The Social Psychology of Telecommunications[J]. Contemporary Sociology, 1976, 7(1):32. 
[22] Orth U R, Limon Y, Rose G. Store-evoked affect, personalities, and consumer emotional attachments to brands[J]. Journal of Business Research, 2010, 63(11):1202-1208.

[23] Jackson M S, White G N, Schmierer C L. Touris m experiences within an attributional framework.[J]. Annals of Tourism Research, 1996, 23(4):798-810.

[24] Trauer B, Ryan C. Destination image, romance and place experience an application of intimacy theory in touris m.[J]. Touris m Management, 2005, 26(4):481-491.

[25] Wu C W. Foreign tourists' intentions in visiting leisure farms 2 [J]. Journal of Business Research, 2015, 68(4):757-762.

[26] Thomson M, Macinnis D J, Park C W. The Ties That Bind: Measuring the Strength of Consumers' Emotional Attachments to Brands[J]. Journal of Consumer Psychology, 2005.

[27] Johnson J W, Rapp A. A more comprehensive understanding and measure of customer help ing behavior[J]. Journal of Business Research, 2010, 63(8):787-792.

[28] Choi N. Information systems attachment: An empirical exploration of its antecedents and its impact on community participation intention[J]. Journal of the A merican Society for Information Science \& Technology, 2013, 64(11):2354-2365.

[29] Shen Y C, Huang C Y, Chu C H, et al. Virtual Community Loyalty: An Interpersonal-Interaction Perspective[J]. International Journal of Electronic Commerce, 2010, 15(1):49-74.
[30] Menon S, Smith D N. Trust me, would i steer you wrong? the influence of peer recommendations within virtual communities[J]. American Journal of Psychiatry, 2002, 142(12):1518-1518.

[31] Kumar N, Benbasat I. Research Note: The Influence of Recommendations and Consumer Reviews on Evaluations of Websites.[J]. Information Systems Research, 2006, 17(4):425-439.

[32] Phang C W, Kankanhalli A, Sabherwal R. Usability and Sociability in Online Communities: A Comparative Study of Knowledge Seeking and Contribution[J]. Journal of the Association for Information Systems, 2009, 10(10):721-747.

[33] Ren Y, Harper F M, Drenner S, et al. Building member attachment in online communities: applying theories of group identity and interpersonal bonds[J]. Mis Quarterly, 2012, 36(3):841-864.

[34] Antioco M, Moenaert R K, Feinberg R A, et al. Integrating service and design: the influences of organizational and communication factors on relative product and service characteristics[J]. Journal of the Academy of Marketing Science, 2008, 36(4):501-521.

[35] Chen Beilei. An empirical study on consumers' online word of mouth Communication based on Network and Trust Theory [D]. Zhejiang University, 2008. (In Chinese)

[36] Zheng Xiaoping. An empirical study on the influence of online reviews on online consumers' purchase decisions [D]. Renmin University of China, 2008. (In Chinese) 